\title{
Patients Discharged Against Medical Advice from a Psychiatric Hospital in Iran: A Prospective Study
}

\author{
Fatemeh Sheikhmoonesi ${ }^{1}$, Mohammad Khademloo ${ }^{2}$ \& Samaneh Pazhuheshgar ${ }^{3}$ \\ ${ }^{1}$ Psychiatry and Behavioral Sciences Research Center, Mazandaran University of Medical Sciences, Sari, Iran \\ ${ }^{2}$ Department of Community Medicine, Mazandaran University of Medical Sciences, Sari, Iran \\ ${ }^{3}$ Mazandaran University of Medical Sciences, Sari, Iran \\ Correspondence: Fatemeh Sheikhmoonesi, MD, Associate Professor of Psychiatry, Psychiatry and Behavioral \\ Sciences Research Center, Zare Hospital, Sari, Iran. Tel: 98-911-353-9217. E-mail: fmoonesi@mazums.ac.ir
}

Received: October 1, 2013 Accepted: January 6, $2014 \quad$ Online Published: March 28, 2014

doi:10.5539/gjhs.v6n3p213 URL: http://dx.doi.org/10.5539/gjhs.v6n3p213

Financial support was provided by Mazandaran University of Medical Sciences

\begin{abstract}
Aim: Self- discharged patients are at high risk for readmission and ultimately higher cost for care. We intended to find the proportion of patients who leave hospital against medical advice and explore some of their characteristics.

Methods: This prospective study of discharge against medical advice was conducted in psychiatric wards of Zare hospital in Iran, 2011. A psychologist recorded some information on a checklist based on the documented information about the patient who wanted to leave against medical advice. The psychologist interviewed these patients and recorded the reasons for discharge against medical advice. Descriptive statistics were calculated for the variables.

Results: The rate of premature discharge was 34.4\%. Compared to patients with regular discharges, patients with premature discharge were significantly more likely to be male, self-employed, to have co morbid substance abuse and first admission and positive family history of psychiatric disorder. Disappearance of symptoms was the most frequent reason for premature discharge.

Conclusion: The $34.4 \%$ rate of premature discharge observed in our study is higher than rate reported in other studies. One possible explanation is our teaching hospital serves a low-income urban area and most patients had low socioeconomic status. Further studies are needed to compare teaching and non-teaching hospital about the rate of premature discharge and the reasons of patients who want to leave against medical advice.
\end{abstract}

Keywords: against medical advice (AMA), discharge, hospital, patient, psychiatry

\section{Introduction}

Discharge against medical advice (AMA) is a prevalent and vexing problem for patients and their psychiatrists (Wung, CC Chen, FC Chen, \& Lin, 2010). Some risks of AMA discharge include younger age, single marital status, male gender, low socioeconomic status, and combined diagnosis of personality or substance use disorder, lack of health insurance and history of numerous hospitalizations ending in AMA discharge (Brook, Hilty, Liu, $\mathrm{Hu}$, \& Frye, 2006; Said, Ibrahim, Kent, \& Eswar, 2007).

Patients who leave hospital against medical advice may be at risk of adverse health outcome and readmission. Stephen, Hwang, Rajesh, Vince and Rochelle (2003) identified increased risk of readmission among general medicine patients who leave hospital AMA is concentrated in the first two weeks after discharge. Some reasons for AMA discharge are dissatisfaction with care, personal, family and financial problems and subjective improvement in symptoms (Said et al., 2007).

The problem in Iran is different from the West in many ways which is linked to cultural differences and the resources available for the care and treatment of mentally ill patients. We intended to find the proportion of patients who leave hospital against medical advice and some of their characteristics in the year 2011. Very little 
research in Iran has been conducted into AMA discharge from psychiatric hospitals. A drawback of the previous studies is that they are retrospective in nature and therefore susceptible to the bias of under-reporting of event. Moreover, they did not explore the reasons for AMA discharge.

As far as we know, this study is the first prospective study in Iran which was carried out through interviews with people who were willing to have AMA discharge. The reasons of AMA discharge are the main concerns of this study. Awareness of the factors involved in AMA discharge is important because of the potential to identify those at higher risk and thereby intervene earlier to prevent adverse consequences.

\section{Materials and Methods}

\subsection{Subjects and Data Collection}

This prospective study of AMA discharge was conducted in psychiatric wards of Zare hospital, a major psychiatric center in the north of Iran. AMA discharge was defined as "patients who signed a standard hospital form acknowledging that they were discharging themselves against medical advice contrary to the advice of their psychiatrist".

\subsection{Participants Recruitment}

Three hundred and sixteen patients who were discharged between 1 January 2011 and 1 January 2012 were randomly assessed. We use simple randomization to choose patients to be interviewed. As soon as AMA discharge was reported by nurses, a psychologist recorded some information on a checklist based on the documented information about the patient including socio-demographic variables, diagnosis according to DSM-IV-TR (Diagnostic and statistical Manual of Mental disorders, 4th edition; American Psychiatric Association, 1994), patients and their caregiver's level of education, substance abuse, number of previous hospitalizations, and family history of psychiatric disorder. The psychologist interviewed the patients and recorded the reasons for AMA discharge on a checklist. More than one reason could be coded for each patient. The data was collected and then analyzed anonymously.

\subsection{Statistical Analysis}

Descriptive statistics were calculated for the variables. X2 test and independent t-test were applied to compare the variables between patients with AMA discharges and those with regular discharges. The data was analyzed using SPSS version 10.0 for windows.

\subsection{Ethical Issues}

This study was approved by the Ethical Committee of Mazandaran University of Medical Sciences. All the patients signed informed consents.

\section{Results}

Of 1171 patients discharged during the study period, 403 patients were discharged AMA. The rate of AMA discharge was $34.4 \%$ according to Molnar \& Pinchoff equation (1993). Three hundred and sixteen patients were randomly assessed. Among the completed questionnaires there were 9 questionnaires with no information on profession and 6 of them did not provide the information on marital status. However, we included these questionnaires since they contained other information.

One hundred and thirty two (41.77\%) were male and 184 (58.22\%) were female. The mean age was $35.1 \pm 11.93$ and $226(71.51 \%)$ were discharged as planned but 90 patients $(28.48 \%)$ were discharged AMA. Compared to patients with regular discharges, AMA discharge patients were significant differences between the groups regarding the age, marital status, educational level, previous suicide attempt. Table 1 summarizes the baseline characteristics of the study sample. AMA discharge was more prevalent in significantly more likely to be male, self-employed, to have co morbid substance abuse and first admission and positive family history of psychiatric disorder. There were no patients admitted for the first time $(\mathrm{P}=0.004)$. 
Table 1. Characteristics of patients who left hospital AMA and patients discharged formally

\begin{tabular}{|c|c|c|c|}
\hline Characteristic & Left AMA $(n=90)$ & Discharged formally $(n=226)$ & Pvalue \\
\hline Sex & & & 0.034 \\
\hline Male & $46(34.8 \%)$ & $86(65.2 \%)$ & \\
\hline Female & $44(23.9 \%)$ & $140(76.1 \%)$ & \\
\hline Mean age & $33.7 \pm 12$ & $35.63 \pm 11.8$ & NS \\
\hline \multicolumn{4}{|l|}{ Profession } \\
\hline Unemployed/housewife & $59(65.6 \%)$ & $187(82.8 \%)$ & \\
\hline Self-employed & $20(22.2 \%)$ & $23(10.17 \%)$ & 0.006 \\
\hline Office worker & $7(7.8 \%)$ & $11(4.82 \%)$ & \\
\hline Missing data & $4(4.4 \%)$ & $5(2.21 \%)$ & \\
\hline Marital Status & & & NS \\
\hline single & $31(34.4 \%)$ & $93(41.1 \%)$ & \\
\hline Married & $41(45.6 \%)$ & $90(40 \%)$ & \\
\hline Widow & $14(15.6 \%)$ & $32(14 \%)$ & \\
\hline Divorced & $0(0 \%)$ & $9(4 \%)$ & \\
\hline Missing data & $4(4.4 \%)$ & $2(0.9 \%)$ & \\
\hline \multicolumn{4}{|l|}{ Educational level } \\
\hline elementary school & $27(30 \%)$ & $69(30.5 \%)$ & NS \\
\hline High school & $47(52 \%)$ & $98(43.4 \%)$ & \\
\hline college & $16(18 \%)$ & $59(26.1 \%)$ & \\
\hline First Admission & $65(65 \%)$ & $96(42 \%)$ & 0.001 \\
\hline Positive family history & $26(21.3 \%)$ & $96(78.7 \%)$ & 0.029 \\
\hline History of substance abuse & $38(42.2 \%)$ & $75(33.1 \%)$ & 0.05 \\
\hline History of suicide attempt & $24(26.7 \%)$ & $36(16 \%)$ & NS \\
\hline
\end{tabular}

NS: not significant statistically.

Among the patients the educational level of 96 was elementary school of whom $28.1 \%$ were discharged against medical advice and $71.9 \%$ were formally discharged. There were 145 patients with educational background at high school level. Amongst them $32.4 \%$ had AMA discharge but $67.6 \%$ had regular discharge. From the total of 75 patients with college education $21.3 \%$ left the hospital AMA while $78.7 \%$ were discharged formally. These figures indicate no significant difference between the two groups regarding educational background.

There were no significant differences between the groups regarding season of admission, the data is presented in Table 2.

Table 2. Season of admission in two groups

\begin{tabular}{llll}
\hline Season & Left AMA $(\mathrm{n}=90)$ & Discharged formally $(\mathrm{n}=226)$ & Pvalue \\
\hline Spring & $16(17 \%)$ & $55(25 \%)$ & \\
Summer & $26(29 \%)$ & $52(23 \%)$ & 0.161 \\
Autumn & $6(7 \%)$ & $29(13 \%)$ & \\
Winter & $42(47 \%)$ & $89(39 \%)$ & \\
\hline
\end{tabular}


Table 3. Reasons for AMA discharge from psychiatric ward

\begin{tabular}{ll}
\hline Reasons for AMA discharge & Frequency \\
\hline Disappearance of symptoms & $32(35.6 \%)$ \\
Lack of insight & $23(25.6 \%)$ \\
Missing family & $17(18.9 \%)$ \\
Boredom from ward environment & $15(16.7 \%)$ \\
Economic problem & $11(12.2 \%)$ \\
Fear of other patients & $9(10 \%)$ \\
Anger over given treatment & $8(8.9 \%)$ \\
Lack of trust to the doctor & $3(3.3 \%)$ \\
Lack of satisfaction with staff behavior & $4(4.4 \%)$ \\
Others & $8(8.9 \%)$ \\
\hline
\end{tabular}

Disappearance of symptoms was the most frequent reason for AMA discharge (Table 3). As shown in Table 4, there was no significant difference between the groups with respect to diagnosis according to DSM-IV-TR.

Table 4. Comparison of diagnosis in two groups

\begin{tabular}{lll}
\hline & Diagnosis Left AMA (n=90) & Discharged formally (n=226) \\
\hline MDD & $13(41.9 \%)$ & $18(58.1 \%)$ \\
Bipolar disorder (type I, II) & $26(25.7 \%)$ & $75(74.35 \%)$ \\
Psychotic disorder & $44(27 \%)$ & $119(73 \%)$ \\
Anxiety Disorder & $7(33.3 \%)$ & $14(66.7 \%)$ \\
Personality Disorder & $5(25 \%)$ & $15(75 \%)$ \\
\hline
\end{tabular}

\section{Discussion}

Self-discharged patients are at high risk for re-admission and ultimately higher costs of care (Anis et al., 2002). These patients are also at high risk for poor follow-up care for medical issues. Understanding the characteristics of patients who leave AMA and gaining insight into their reasons are great importance since delivery of medical care and quality of care are affected (Said et al., 2007). Prospective nature of this study with the opportunity to interview the patients and investigate their reasons to AMA discharge was an advantage of this study. We found that $34.4 \%$ of psychiatric hospitalization ended in patients leaving against medical advice. The $34.4 \%$ rate of discharge AMA observed in our study is higher than other rate reported in previous studies (Tavallaei et al., 2006; Said et al., 2007; Wung et al., 2010) one possible explanation is our hospital serves a low-income urban area and most patients had low socioeconomic status.

Weingart, Davis and Phillips (1998) reported male gender to be associated with AMA discharge. Our observations and those of others (Saitz et al., 1999; Jeremiah, O'Sullivan, \& Stein, 1995) confirm these findings. Perhaps men are willing to come back home earlier for economic reasons since they feel most responsible for their family's income. Another possible explanation contributing to AMA discharges is that male patients are more likely to have a higher risk of poor medical adherence than female patients (Nose, Barbui, \& Tansella, 2003), poor medical adherence leads to premature discharge consequently (Wung et al., 2010).

Patients with positive family history are less likely to leave against medical advice. One explanation might be that caregivers are more aware of psychiatric disorders and feel worried of not being able to provide better care at home.

Data analysis revealed more AMA discharge amongst self-employed, probably because they were more worried about their jobs while other patients such as office workers had the advantage of sick leave .

We found that the rate of AMA discharge was more prevalent among patients hospitalized for the first time, this may be due to unfamiliarity of the patient or his caregiver with hospital environment thereby resisting 
hospitalization .In addition they are not aware of the course and probability of recurrence in psychiatric disorder.

Data analysis showed substance abuse as a risk factor for irregular discharge. There are some studies in support of this finding that substance abuse could increase the risk of AMA discharge (Gillis, Russell, \& Busby, 1997; Glick, Braff, Johnson, \& Showstack, 1981; Ahmadi et al., 2006; Saitz et al., 2002). Perhaps patients with substance abuse are unwilling to stay in hospital, as hospital stay makes it difficult for them to obtain the required substance. Chan, Palepu and Guh (2004) found that AMA discharges were less likely among injection drug abusers if they were receiving methadone in the hospital. Protocols to treat alcohol and opioid withdrawal to reduce AMA discharge have not been studied yet. Given the high prevalence of AMA discharges in these patients; this would be a worthy area of studying.

Data analysis showed that there was not any significant difference between two groups with respect to diagnosis but Brook et al. (2006) found antisocial personality disorder to be associated more with AMA discharge.

In our study, AMA discharge was not different among different seasons. The authors carried out a study about patients absconding from Zare hospital. In that study we found absconding was more frequent in summer (Sheikhmoonesi, Kabirzadeh, Yahyavi, \& Mohseni, 2012).

We found that age and educational level were not the risk factor for irregular discharge. This conclusion is similar with those found in other studies carried out in Iran (Ahmadi et al., 2006). In most studies conducted in developed countries younger patients and those with low level of education most frequently discharged against medical advice (Senior \& Kabbee, 1986; Ferber et al., 1985). It is difficult to explain the reason, nevertheless it could depends on cultural factors. Smith (1982) proposed that differences in hospital setting, client population and therapists' variety might be the cause of differences between the risk factors of a premature discharge.

Interviewing the patients in order to find the reasons for AMA discharge was done and the results of this study have shown disappearance of symptoms (feeling better) and lack of insight as the main reasons. The tolerance to hospitalization reduces if a person does not believe in his/her disease so proper orientation and psycho educational session during the early treatment phase is essential to keep the patient in hospital.

Targum, Capodanno, Hoffman and Foudraine (1982) found an approximately 30\% decrease in total AMA discharges among psychiatric inpatients that used a nurse as a patient advocate. The advocate's responsibility was to help explore a patient's preconceptions about hospitalization and to address fears and complaints about it.

Limitation: Our results should be interpreted with several limitations in mind. The length of stay at hospital and its relationship with AMA discharge was not assessed. Our study was done in a teaching hospital so we cannot generalize our findings to other hospitals. Larger studies are needed to compare teaching and non-teaching hospitals about the rate of AMA discharge and the reasons of patients who want to leave AMA.

\section{Conclusion}

Awareness of the factors involved in AMA discharge is important because of the potential to identify those at higher risk and thereby intervene earlier to prevent adverse consequences. Male gender, self-employed, to have co morbid substance abuse and previous hospitalizations and positive family history of psychiatric disorder are risk factors to discharge against medical advice.

\section{Acknowledgments}

The authors wish to thank all the nurses in psychiatry wards in Zare hospital, Sari, Iran.

\section{References}

Ahmadiabhari, S. A., Monirabbasi, M., Jafarnejad, P., \& Zerrati, H. (2006). Factors Associated With Premature Discharge of Patients With Psychosis Against Medical Advice. Iran J Psychiatry, 1, 27-30.

American Psychiatric Association. (1994). Diagnostic and Statistical Manual of Mental Disorders (4th edition) (DSM-IV). Washington DC: American Psychiatric Association.

Anis, A. H., Sun, H., Guh, D. P., Palepu, A., Schechter, M. T., \& O’Shaughnessy, M. V. (2002). Leaving hospital against medical advice among HIV-positive patients. CMAJ, 167, 633-637.

Brook, M., Hilty, D. M., Liu, W., Hu, R., \& Frye, M. A. (2006). Discharge against medical advice from inpatient

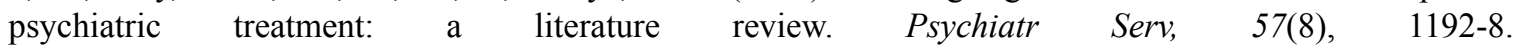
http://dx.doi.org/10.1176/appi.ps.57.8.1192

Chan, A. C., Palepu, A., \& Guh, D. P. (2004). HIV-positive injection drug users who leave the hospital against medical advice: the mitigating role of methadone and social support. J Acquir Immune DeficSyndr, 35(1), 56-59. http://dx.doi.org/10.1097/00126334-200401010-00008 
Ferber, J. S., Oswald, M., Rubin, M., Ungemack, J., \& Schane, M. (1985). The day hospital as entry point to a network of long-term services: a program evaluation. Hosp Community Psychiatry, 36, 1297-301.

Gillis, K., Russell, V. R., \& Busby, K. (1997). Factors associated with unplanned discharge from psychiatric day treatment programs, a multi center study. General hospital psychiatry, 19, 355-61. http://dx.doi.org/10.1016/S0163-8343(97)00052-2

Glick, I. D., Braff, D. L., Johnson, G., \& Showstack, J. A. (1981). Outcome of irregularly discharged psychiatric patients. Am J psychiatry, 138, 1472-6.

Jeremiah, J., O’Sullivan, P., \& Stein, M. D. (1995). Who leaves against medical advice? J Gen Intern Med, 10, 403-405. http://dx.doi.org/10.1007/BF02599843

Molnar, G., \& Pinchoff, D. M. (1993). Factors in patient elopements from an urban state hospital and strategies for prevention. Hosp Community Psychiatry, 44, 791-92.

Nose, M., Barbui, C., \& Tansella, M. (2003). How often do patients with psychosis fail to adhere to treatment programmes? A systematic review. Psychol. Med., 33(7), 1149-1160. http://dx.doi.org/10.1017/S0033291703008328

Said, A., Ibrahim, C., Kent, K., \& Eswar, K. (2007). Factors Associated With Patients Who Leave Acute-Care Hospitals Against Medical Advice. Am J Public Health, 97(12), 2204-2208. http://dx.doi.org/10.2105/AJPH.2006.100164

Saitz, R., Ghali, W. A., \& Moskowitz, M. A. (1999). Characteristics of patients with pneumonia who are discharged from hospital against medical advice. Am $J$ Med, 107, 507-509. http://dx.doi.org/10.1016/S0002-9343(99)00262-4

Saitz, R. (2002). Discharges against medical advice: time to address the causes. CMAJ, 167(6), 647-648.

Senior, N., \& Kibbee, P. (1986). Can we predict the patient who leaves against medical advice: The_search for a method. Psychiatr Hosp, 17, 33-36.

Sheikhmoonesi, F., Kabirzadeh, A., Yahyavi, S. T., \& Mohseni, B. (2012). A prospective study of patients absconding from a psychiatrichospital in Iran. Medicinski Glasnik, 9, 346-350.

Smith, H. H. Jr. (1982). Discharge against medical advice (AMA) from an acute care private psychiatric hospital. J Clin Psychol, 38, 550-4. http://dx.doi.org/10.1002/1097-4679(198207)38:3<550::AID-JCLP2270380313> 3.0.CO;2-Q

Stephen, W., Hwang, J. L., Rajesh, G., Vince, C., \& Rochelle, E. M. (2003). What happens to patients who leave hospital against medical advice? CMAJ, 168(4), 417-420.

Targum, S. D., Capodanno, A. E., Hoffman, H. A., \& Foudraine, C. (1982). An intervention to reduce the rate of hospital discharges against medical advice. Am J Psychiatry, 139(5), 657-659.

Tavallaei, S. A., Asari, Sh., Habibi, M., Khodami, H. R., Siavoshi, Y., \& Nouhi, S. (2006). Discharge Against Medical Advice from Psychiatric Ward. Journal of Military Medicine, 8, 24-30.

Weingart, S. N., Davis, R. B., \& Phillips, R. S. (1998). Patients discharged against medical advice from a general medicine service. J Gen Intern Med, 13, 568-571. http://dx.doi.org/10.1046/j.1525-1497.1998.00169.x

Wung, Y. T., Chen, C. C., Chen, F. C., \& Lin, C. H. (2010). Schizophrenia patients discharged against medical advice at a mental hospital in Taiwan. Psychiatry Clin Neurosci, 64(4), 415-20. http://dx.doi.org/10.1111/j.1440-1819.2010.02103.x

\section{Copyrights}

Copyright for this article is retained by the author(s), with first publication rights granted to the journal.

This is an open-access article distributed under the terms and conditions of the Creative Commons Attribution license (http://creativecommons.org/licenses/by/3.0/). 